\title{
Sport Science on Women, Women in Sport Science
}

As I, Iñigo Mujika, write these words, I have just completed the third week of an altitude training camp in Sierra Nevada, Spain $(2320 \mathrm{~m})$ in preparation for the 18th FINA World Championships to be held in Gwangju, South Korea, from July 12 to 28, 2019. As usual in a situation like this, I am providing sport physiology support to elite athletes, including some Olympic and world champions. The only "special" thing about this particular training camp is that a large majority of the athletes I am working with are women: pool swimming, 2 women; open-water swimming, 2 women and 4 men; and water polo, 22 women. As I look back on my career in sport physiology, I realize that I have often had the opportunity to work with elite women athletes. Indeed, my very first scientific article as a $\mathrm{PhD}$ student reported, "The subjects of this study were 18 national and international level swimmers, 10 males and 8 females."1 In my second PhD study, however, we wanted to look at hormonal variations during periods of intensive training and tapering, and although we still had access to the same group of swimmers, we chose to study only men: "Eight highlytrained national and international level male swimmers participated in this study." As far as I can remember, the only reason to exclude women from the investigation was that "female hormones were too complicated."

Nevertheless, and setting aside the times I worked in professional cycling and professional football, primarily with male athletes, I have closely worked indistinctively with both women and men in various endurance and team sports, either as a sport physiologist or as a coach, and never thought twice about the fact that it was women I was working with-just elite athletes . . . period.

My involvement with elite women athletes on the field, however, did not translate into a balanced ratio of scientific papers on female and male athletes. Indeed, on review, only $6 \%$ of my scientific studies involved exclusively female athletes (soccer and water polo players, synchronized swimmers, and a female triathlete), whereas about $23 \%$ included both female and male participants. A similar trend can be observed by looking at the first 5 issues of the International Journal of Sports Physiology and Performance (IJSPP) published in 2019: Only 19\% of all original investigations and brief reports included female subjects, and a meager $4 \%$ were exclusively performed on female athletes: 2 studies were conducted on synchronized swimmers (now called artistic swimmers), 1 on handball players, and 1 on soccer players.

By contrast, one of us (R.S.T.) has made a career in sport science by mainly studying women and sex differences in responses and adaptations to training. ${ }^{3-5}$ As a former college-level endurance athlete and coach-turned scientist, she was surprised at the beginning of her scientific career by the smaller amount of research completed on women. She, too, encountered the idea that the innate hormonal fluctuations that women experience are "complicated and time-consuming" compared with those of men. Experience and experiments have, however, demonstrated that research on women simply requires additional planning and that most women who participate in sport-science research are so interested in their own physiology and performance that they, too, will "go the extra mile" (eg, monitoring their menstrual cycle and communicating with researchers) to contribute.

The performance difference between the world's best male and female athletes has been more or less stable at $\sim 8 \%$ to $12 \%$ across a range of sports. ${ }^{6}$ While this gap has decreased slightly due to increased participation and the opportunity for more women to train and compete professionally, there are many unexplored or only superficially explored research paradigms that could contribute to decreasing this performance gap. It is imperative to recognize previous sport-science research on women, including some recent books, ${ }^{7,8}$ but it is also worth remembering that much of the research used for exercise testing and prescription, as well as in the medical field, has been completed on male participants. Historically, women and their reproductive systems have been considered "fragile," and the mandate to require the examination of sex as a biological variable in scientific research and ensure that results can be relevant to both women and men is relatively young. ${ }^{9}$ The fact remains that women are significantly underrepresented in sport and exercise research, with less than $40 \%$ of participants included in publications of 3 major sport-science journals being women. ${ }^{10}$ Considering the growing number of women currently participating in competitive sport, this statistic is concerning. It is well established that the physiology of women is unique and driven in large part by endogenous sex hormones that regulate the menstrual cycle. Also unique to women is the ability to legally and ethically alter their hormonal profile and menstrual cycle by using exogenous hormones (hormonal contraceptives). Approximately $42 \%$ of exercising women believe that their menstrual cycle has a negative impact on exercise training and performance. ${ }^{11}$ Approximately $50 \%$ of elite athletes are currently using hormonal contraceptives, and up to $70 \%$ have used them. ${ }^{12}$ Unfortunately, we still do not fully understand the effects of the menstrual cycle and hormonal contraceptives on training and performance.

Future sport-science research on both recreational and elite populations should increase the number of women participants, as well the number of studies completed exclusively on women. When including men and women in the same studies, it would benefit readers and practitioners if the results were presented separately, with discussion of the possible influence of sex or reproductive hormones on outcome measures. Monitoring and reporting of menstrual-cycle phase takes a little extra time and effort but could explain "interesting" results. More research should test women in different phases of the menstrual cycle to further elucidate the possible phase effects on training responses, adaptations, and performance (instead of just testing in the follicular, or "low-hormone," phase of the menstrual cycle, when hormonal profile is "most similar" to that of men). When applicable, use of accurate measurements for determination of both ovulation and nonovulatory cycles may also be important (a menstrual bleed does not necessarily indicate ovulation). Users of hormonal contraceptives should be included in research in their own group to further elucidate the possible effects of exogenous hormones on training adaptations and performance, and the type and delivery methods of hormonal contraceptives should be reported. It would also be of 
benefit for researchers to consider the potential underlying issues that might have been a reason for using hormonal contraceptives (eg, relative energy deficiency in sport, polycystic ovary syndrome, endometriosis, etc), as these may have influenced endogenous hormone profiles prior to taking hormonal contraceptives. ${ }^{13-15}$

Unfortunately, the bias favoring male athletes as research subjects can also be clearly observed in sport-science authorship. For instance, only $18 \%$ of my coauthor sport scientists over the years are women (36 out of 196), and a simple count of female and male authors in the first 5 issues of IJSPP published in 2019 indicates that only $13 \%$ were women. While the world of elite sport is evolving and women have achieved leadership positions in both coaching and science/academia, both the scientific and practical fields are, in large part, still dominated by men. This, too, is changing, but a certain degree of awareness and self-reflection is required by sport scientists (both men and women alike) to examine their own possible sociocultural biases ${ }^{16}$ when selecting speakers for international conferences, reviewers for papers and grant proposals, and scientists to cite in research papers, as well as when choosing coauthors and collaborators for new scientific endeavors and planning of future research.

In the meantime, the FIFA Women's World Cup 2019 is being played in France, but we would not be surprised if many of our readers have not even heard about it, despite the fact that viewership records for the event are on track to be broken globally! We hope that these lines will encourage the sportscience community in general and the authors submitting their research to IJSPP in particular to direct our research efforts toward female athletes so that we can increase our understanding of women's sport physiology and performance and to facilitate the access of female sport scientists to research and practitioner positions that may increase scientific outputs and authorship in the published research records.

Iñigo Mujika, Associate Editor, IJSPP Ritva S. Taipale, Researcher, University of Jyväskylä

\section{References}

1. Mujika I, Chatard JC, Busso T, Geyssant A, Barale F, Lacoste L. Effects of training on performance in competitive swimming. Can J Appl Physiol. 1995;20(4):395-406.

2. Mujika I, Chatard JC, Padilla S, Guezennec CY, Geyssant A. Hormonal responses to training and its tapering off in competitive swimmers: relationships with performance. Eur J Appl Physiol Occup Physiol. 1996;74(4):361-366. PubMed ID: 8911829

3. Myllyaho MM, Ihalainen JK, Hackney AC, et al. Hormonal contraceptive use does not affect strength, endurance, or body composition adaptations to combined strength and endurance training in women [published online ahead of print June 20, 2018]. J Strength Cond Res. PubMed ID: 29927884 doi:10.1519/JSC.0000000000002713
4. Ihalainen JK, Hackney AC, Taipale RS. Changes in inflammation markers after a 10-week high-intensity combined strength and endurance training block in women: the effect of hormonal contraceptive use. J Sci Med Sport. 2019;22(9):1044-1048. PubMed ID: 31186194 doi:10.1016/j.jsams.2019.04.002

5. Taipale RS, Häkkinen K. Acute hormonal and force responses to combined strength and endurance loadings in men and women: the “order effect”. PLoS ONE. 2013;8(2):e55051. PubMed ID: 23408956 doi:10.1371/journal.pone.0055051

6. Sandbakk $\varnothing$, Solli GS, Holmberg HC. Sex differences in worldrecord performance: the influence of sport discipline and competition duration. Int J Sports Physiol Perform. 2018;13(1):2-8. PubMed ID: 28488921 doi:10.1123/ijspp.2017-0196

7. Hackney AC, Ed. Sex Hormones, Exercise and Women: Scientific and Clinical Aspects. Cham, Switzerland: Springer; 2016.

8. Forsyth J, Roberts CM, Eds. The Exercising Female: Science and Its Application. Abingdon, UK: Routledge; 2018.

9. National Institutes of Health, Office of Extramural Research. NIH Policy and Guidelines on the Inclusion of Women and Minorities as Subjects in Clinical Research. Bethesda, MD: US Department of Health and Human Services; 2017. https:/grants.nih.gov/grants/ funding/women_min/guidelines.htm.

10. Costello JT, Bieuzen F, Bleakley CM. Where are all the female participants in sports and exercise medicine research? Eur J Sport Sci. 2014;14(8):847-851. PubMed ID: 24766579 doi:10.1080/17461391. 2014.911354

11. Bruinvels G, Burden RJ, McGregor AJ, et al. Sport, exercise and the menstrual cycle: where is the research? $\mathrm{Br} J$ Sports Med. 2017;51(6):487-488. PubMed ID: 27267895 doi:10.1136/bjsports2016-096279

12. Martin D, Sale C, Cooper SB, Elliott-Sale KJ. Period prevalence and perceived side effects of hormonal contraceptive use and the menstrual cycle in elite athletes. Int J Sports Physiol Perform. 2018; 13(7):926-932. PubMed ID: 29283683 doi:10.1123/ijspp.20170330

13. Elliott-Sale KJ, Smith S, Bacon J, et al. Examining the role of oral contraceptive users as an experimental and/or control group in athletic performance studies. Contraception. 2013;88(3):408412. PubMed ID: 23312929 doi:10.1016/j.contraception.2012. 11.023

14. Sims ST, Heather AK. Myths and methodologies: reducing scientific design ambiguity in studies comparing sexes and/or menstrual cycle phases. Exp Physiol. 2018;103(10):1309-1317. PubMed ID: 30051938 doi:10.1113/EP086797

15. Stachenfeld NS. Including women in research. It's necessary, and really not so hard to do. Exp Physiol. 2018;103(10):1296-1297. PubMed ID: 30079983 doi:10.1113/EP087261

16. Bekker S, Ahmed OH, Bakare U, et al. We need to talk about manels: the problem of implicit gender bias in sport and exercise medicine. Br J Sports Med. 2018;52:1287-1289. PubMed ID: 29550755 doi:10. 1136/bjsports-2018-099084 